\title{
A case of a horseshoe appendix
}

\author{
Kazuya Takabatake* (D), Jun Ikeda, Hirotaka Furuke, Chikage Kato, Takuya Kishimoto, Tatsuya Kumano, \\ Kenichiro Imura, Katsumi Shimomura, Takeshi Kubota, Fumihiro Taniguchi and Yasuhiro Shioaki
}

\begin{abstract}
Anomalies of the appendix are extremely rare, and a horseshoe appendix is even rarer. A literature search has revealed only five reported cases. In this report, we present a case of a horseshoe appendix.

A 78-year-old man was referred for further examination following a positive fecal occult blood test. A mass in his ascending colon was detected on colonoscopy, while computed tomography showed that it was connected to the appendix. Tumor invasion derived from the ascending colon or appendix was suspected. We diagnosed ascending colon cancer prior to laparoscopic ileocecal resection. Macroscopic findings showed that the appendix connected to the back side of the mass, while microscopic findings showed that the mucosa and submucosa were continuous from the appendiceal orifice in the cecum to the other orifice in the ascending colon, where a type 1 tumor was observed on the orifice. We eventually diagnosed the patient with tubulovillous adenoma and a horseshoe appendix.

A horseshoe appendix communicates with the colon at both ends and is supplied by a single fan-shaped mesentery. Cases are classified by the disposal of the mesentery and the location of the orifice. Anatomical anomalies should be considered despite the rarity of horseshoe appendices.
\end{abstract}

Keywords: Anomalies of the appendix, Horseshoe appendix

\section{Background}

Anomalies of the appendix are extremely rare. There have been several reports on the absence or duplication of the appendix. However, a literature search revealed only five reported cases of a horseshoe-shaped appendix [1-5]. In this report, we present a case of a horseshoe appendix that was incidentally found during resection of an adenoma in the ascending colon.

\section{Case presentation}

A 78-year-old man was referred to us for further examination following a positive fecal occult blood test result. A mass that was possibly malignant was detected by colonoscopy in the ascending colon. There were no particular findings from physical examinations or hematological examinations, including the following tumor markers: cancer embryonic antigen and cancer antigen 19-9. Colonoscopy showed a type 1 mass in

\footnotetext{
* Correspondence: kazuya-takabatake@kyoto1-jrc.org

This case report was presented at the poster presentation of The 77rd

Annual Congress of Japan Surgical Association. Kazuya Takabatake is the first author.

Department of Surgery, Japanese Red Cross Kyoto Daiichi Hospital, 15-749 Honmachi, Higashiyama, Kyoto, Kyoto, Japan
}

the ascending colon (Fig. 1) with submucosal invasion suspected from poor mobility. Computed tomography showed a 30-mm-wide mass in the ascending colon (Fig. 2) that was connected to the appendix. Tumor invasion derived from the ascending colon or appendix was suspected (Fig. 3). We preoperatively diagnosed ascending colon cancer, as follows: cT1, cN0, cM0, cStage1 (UICC/AJCC 7th). A standard laparoscopic ileocecal resection was then performed. Intraoperative findings showed that the appendix was connected to the ascending colon. It was suspected to be a tumor invasion and was therefore mobilized and resected carefully. Macroscopic findings showed the appendix connected to the back side of the mass, inserting along the appendiceal orifice and reaching the adenoma of the ascending colon (Figs. 4 and 5). Microscopic findings revealed that the mucosa and submucosa were continuous from the appendiceal orifice in the cecum to the other orifice in the ascending colon with a seamless muscular layer (Fig. 6). There was no evidence of inflammation or malignancy, and pathologically, the appendix was normal. There was a type 1 tumor on the orifice in the 


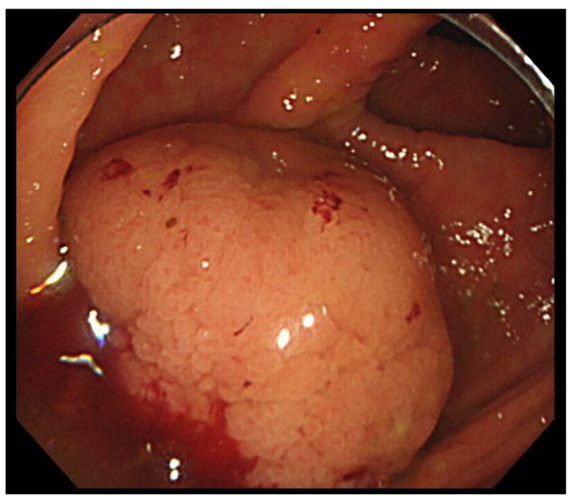

Fig. 1 A type 1 mass detected in the ascending colon. Sub-mucosal invasion suspected from poor mobility

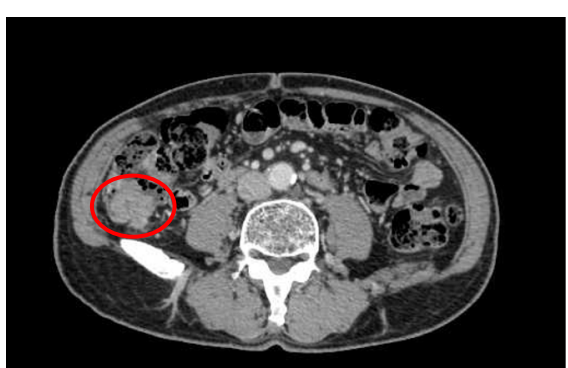

Fig. 2 A 30-mm-wide mass in the ascending colon

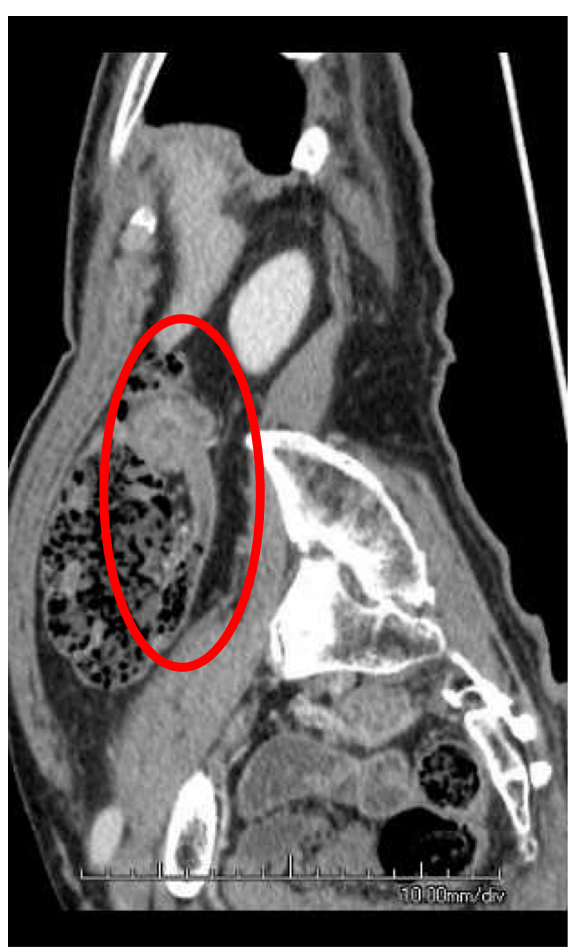

Fig. 3 A mass connected with the appendix. Tumor invasion derived from the ascending colon or appendix suspected
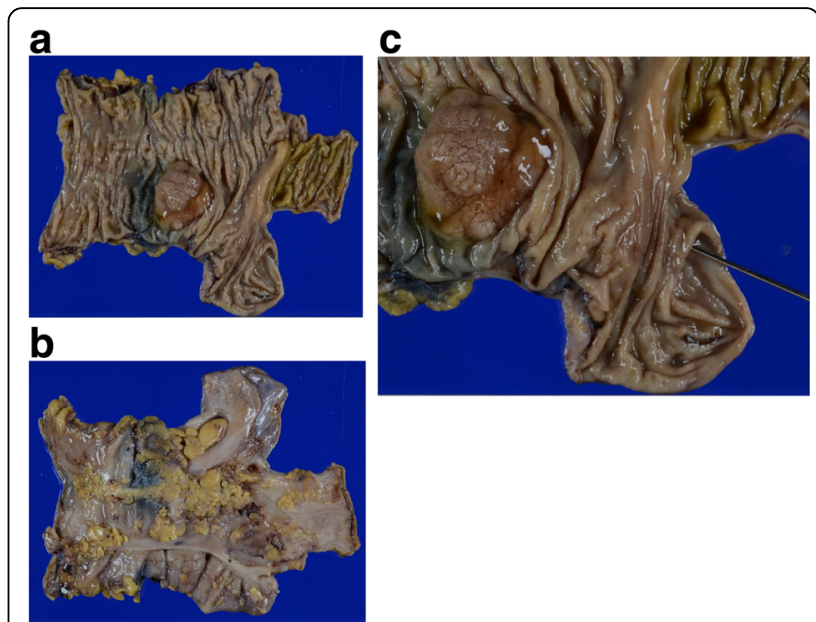

Fig. 4 Resected specimen (a, b). Appendix connected to the back side of the mass, inserting along the appendiceal orifice and reaching the adenoma of the ascending colon (c)
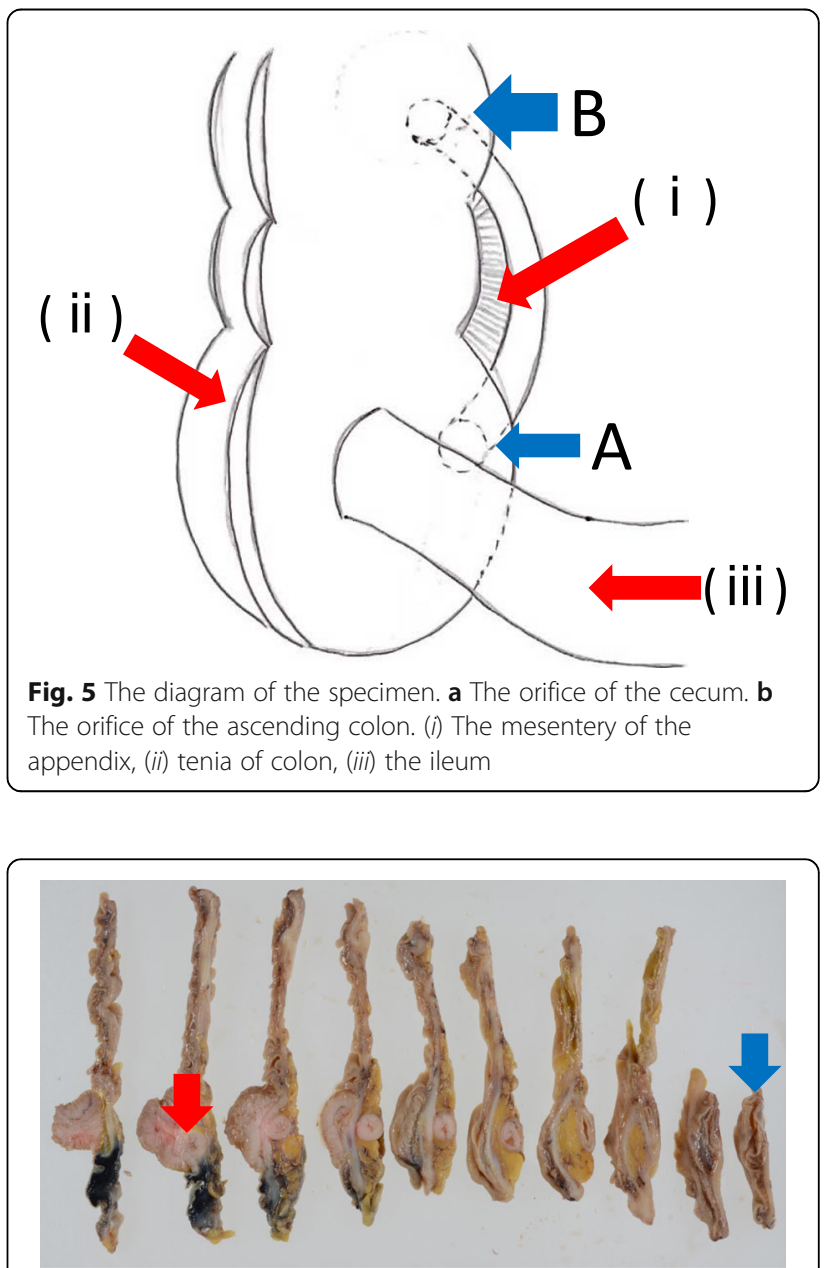

Fig. 6 Mucosa and submucosa were continuous from the appendiceal orifice in the cecum to the other orifice in the ascending colon with a seamless muscular layer. A blue arrow is the orifice of the cecum, and a red arrow is the other of the ascending colon 
Table 1 Cases of a horseshoe appendix

\begin{tabular}{|c|c|c|c|c|c|c|c|c|c|}
\hline Author & Year & Age & Sex & Diagnosis & Operation & Type & Orifice & $\begin{array}{l}\text { Other } \\
\text { anomalies }\end{array}$ & $\begin{array}{l}\text { Detection of a } \\
\text { horseshoe appendix }\end{array}$ \\
\hline $\begin{array}{l}\text { Mesko TW } \\
\text { et al. }\end{array}$ & 1989 & 33 & Male & Sigmoid diverticulitis & $\begin{array}{l}\text { Sigmoidectomy + } \\
\text { appendectomy }\end{array}$ & Frontal & $\begin{array}{l}\text { Cecum- } \\
\text { cecum }\end{array}$ & None & Incidentally \\
\hline $\begin{array}{l}\text { DasGupta R } \\
\text { et al. }\end{array}$ & 1999 & 48 & Male & Cecum perforation & $\begin{array}{l}\text { Suturing perforation + } \\
\text { appendectomy }\end{array}$ & Frontal & $\begin{array}{l}\text { Cecum- } \\
\text { cecum }\end{array}$ & None & Incidentally \\
\hline $\begin{array}{l}\text { Calotă F } \\
\text { et al. }\end{array}$ & 2010 & 43 & Female & Appendicitis & Appendectomy & Sagittal & $\begin{array}{l}\text { Cecum- } \\
\text { cecum }\end{array}$ & None & Incidentally \\
\hline $\begin{array}{l}\text { Cem ORUÇ } \\
\text { et al. }\end{array}$ & 2013 & 64 & Female & Appendicitis & Appendectomy & Sagittal & $\begin{array}{l}\text { Cecum- } \\
\text { cecum }\end{array}$ & None & Incidentally \\
\hline $\begin{array}{l}\text { Ch Gyan } \\
\text { Singh }\end{array}$ & 2016 & 4 & Male & Appendicitis & Appendectomy & Sagittal & $\begin{array}{l}\text { Cecum- } \\
\text { cecum }\end{array}$ & None & Incidentally \\
\hline Our case & & 78 & Male & $\begin{array}{l}\text { Adenoma in } \\
\text { ascending colon }\end{array}$ & $\begin{array}{l}\text { Laparoscopic ileocecal } \\
\text { resection }\end{array}$ & Frontal & $\begin{array}{l}\text { Cecum- } \\
\text { ascending colon }\end{array}$ & None & Incidentally \\
\hline
\end{tabular}

ascending colon, which was pathologically diagnosed as a tubulovillous adenoma with moderate atypia, along with an appendiceal extension. There was no evidence of lymph node metastasis. We finally diagnosed the patient with a tubulovillous adenoma and a horseshoe appendix. After undergoing the previously described surgery, the patient experienced a paralytic ileus and required fasting. He was discharged home on the 15 th day after surgery.

\section{Discussion}

Anomalies of the appendix are extremely rare. In a study by Collins, from among 50,000 appendix specimens,

Table 2 The classification of appendiceal anomalies

-Number anomalies
1. Agenesis: absence of appendix
2. Duplex appendix
A: partial duplication with both appendices sharing a common base like
"Y-shaped" on a single cecum
B: complete duplication of the appendix on a single cecum
-B1 avian type: two appendices symmetrically placed on either side of
the ileocecal valve
-B2 tenia-coli cecum type: one appendix arising from the usual site of
the cecum and the other arising from the cecum along the tenia
-B3 tenia-coli hepatic flexure type: one appendix arising from the usual
site of the cecum and the other arising from the hepatic flexure of the
colon along the tenia.
-B4 tenia-coli splenic flexure type: one appendix arising from the usual
site of the cecum and the other arising from the splenic flexure of the
colon along the tenia.
C: duplication of the cecum, each having its own appendix
3. Triplex appendix: complete triplication of appendix on the cecum
- Shape anomalies
Horseshoe Appendix
Disposal of the mesentery
- Sagittal disposal: the both bases of the appendix along the tenia in
- Frontal disposal: the bases of the appendix not on the tenia
- Cocation of the orifice
- Cecum-cecum

there were four cases of agenesis and two of duplication [6]. Duplications of the appendix were classified by Cave in 1936 [7] and modified by Wallbridge in 1963 [8] and Biermann in 1993 [9]. However, there were some cases that could not be classified using this classification (e.g., triplets of the appendix, horseshoe appendix).

Based on our review of the literature, our patient is the 6th reported case of a horseshoe-shaped appendix. Such an appendix is said to communicate with the colon at both ends and to be supplied by a single fan-shaped mesentery. We analyzed the five reported cases (Table. 1; our case plus the five previously reported), including four men and two women who ranged in age from 4 to 78 years (average 45 ). No case was diagnosed with a horseshoe appendix preoperatively, and the appendix was removed in all cases, including an ileocecal resection. The patients had no other anomalies and could be classified into two types based on the disposal of the mesentery and the location of the orifice: three frontal types, with the bases of the appendix located not on the tenia, and three sagittal types, with the bases along the tenia. The five previously reported cases showed that the appendix communicated with the cecum at both ends; only our case showed communication from the cecum to the ascending colon. There was no case in which an adenoma existed on the other orifice. There was one report in which a mucinous cystadenocarcinoma of the appendix invaded the ascending colon with fistula formation [10]. It could be argued that our case did not represent an anomaly of the appendix, but rather a fistula caused by an appendiceal neoplasm. However, we believe that our case represented a horseshoe appendix because the neoplasm on the other orifice was an adenoma, not a malignancy, and the mucosa and submucosa of the appendix were continuous, with a seamless muscular layer.

Calota et al. reported a more complete classification system of the anomalies of the appendix [3], which we modified (Table 2). 
In this classification, anomalies of the appendix are classified by number (e.g., agenesis, duplication, and triplet) and shape (e.g., horseshoe), while anomalies of the horseshoe appendix are further classified by the disposal of the mesentery and the location of the orifice.

\section{Conclusions}

Although most surgeons will not experience anomalies of the appendix, including the horseshoe appendix, anatomical anomalies of appendix should nevertheless be considered, despite their rarity.

\section{Authors' contributions}

All authors participated in the management of the patient in this case report. KT performed literature review and drafted the manuscript. JI supervised the case and also supervised the writing of the manuscript. YS is a chairperson of our department and supervised the entire process. All authors read and approved the final manuscript.

\section{Competing interests}

The authors declare that they have no competing interests.

\section{Consent for publication}

Written informed consent was obtained from the patient for the publication

of this case report and any accompanying images.

Received: 13 July 2016 Accepted: 9 November 2016

Published online: 23 November 2016

\section{References}

1. Mesko TW, Lugo R, Breitholtz T. Horseshoe anomaly of the appendix: a previously undescribed entity. Surgery. 1989;106(3):563-6.

2. DasGupta R, Reber PU, Patel AG. Horseshoe appendicitis. Eur J Surg. 1999;165(11):1095-6.

3. Calotă F, Vasile I, Mogoantă S, Zavoi R, Pașalega M, Moraru E, Stoicea C. Horseshoe appendix: an extremely rare anomaly. Chirurgia (Bucur). 2010;105:271-4.

4. Cem ORUÇ, Özgen IŞIK, Orhan ÜREYEN, Oytun Saffet KAHYAOĞLU, Ayhan KÖSEOĞLU. An extremely rare appendidfceal anomaly: horseshoe appendicitis. Ulus Travma Acil Cerrahi Derg. 2013;19(4):385-6.

5. Singh CG, Nyuwi KT, Rangaswamy R, Ezung YS, Singh HM. Horseshoe appendix: an extremely rare appendiceal anomaly. J Clin Diagn Res. 2016;10(3):25-6

6. Collins DC. A study of 50,000 specimens of the human vermiform appendix. Surg Gynecol Obstet. 1955;101(4):437-45.

7. Cave AJE. Appendix vermiformis duplex. J Anat. 1936:70:283-92.

8. Wallbridge PH. Double appendix. Br J Surg. 1963;50:346-7.

9. Biermann R, Borsky D, Gogora M. Die appendicitis duplex-eine pathologische raritat. Chirurg. 1993;64:1059-61.

10. Miyakura $Y$, Iwai H, Togashi K, Horie H, Nagai H, Kishaba Y, Sato K, Azuma H. Mucinous cystadenocarcinoma of the appendix invading the ascending colon with fistula formation: report of a case. Surg Today. 2007;37(9):806-10.

\section{Submit your manuscript to a SpringerOpen ${ }^{\circ}$ journal and benefit from:}

- Convenient online submission

- Rigorous peer review

- Immediate publication on acceptance

- Open access: articles freely available online

- High visibility within the field

- Retaining the copyright to your article 